\title{
Natural history and long-term outcome of patients treated for early stage colorectal cancer
}

\author{
Hugh James Freeman MD CM FRCPC
}

\begin{abstract}
HJ Freeman. Natural history and long-term outcome of patients treated for early stage colorectal cancer. Can J Gastroenterol 2013;27(7):409-413.
\end{abstract}

BACKGROUND: The long-term natural history of early stage colon cancer and the outcome of long-term colonoscopic surveillance in routine specialist clinical practice after removal of the incident cancers have not been fully defined. In the present long-term evaluation up to 25 years, metachronous neoplasia, including both advanced adenomas and carcinomas, was defined.

METHODS: All early stage colorectal cancer patients evaluated consecutively from a single clinical practice underwent follow-up colonoscopic evaluations after removal of the incident cancer and clearing of neoplastic disease. Colonoscopic surveillance was planned for two phases - initially on an annual basis for five years, followed by continued surveillance every three years up to 25 years with removal of any metachronous neoplastic lesion.

RESULTS: A total of 128 patients ( 66 men and 62 women) with 129 incident early stage colorectal cancers were evaluated. Virtually all patients were symptomatic, usually with clinical evidence of blood loss. Incident early cancers were located throughout the colon, especially in the rectosigmoid, and showed no pathological evidence of nodal or other metastases. All patients evaluated during the first five years did not experience recurrent disease or have metachronous cancer detected. After five years, a total of 94 patients were evaluated up to 25 years; six of these patients were found to have seven metachronous colon cancers. All developed cancer more than seven years after removal of the incident colorectal cancer, including six asymptomatic adenocarcinomas, of which only one had evidence of single node involvement. Another patient in this cohort developed a poorly differentiated neuroendocrine carcinoma of the colon. In addition, $45 \%$ of patients had a total of 217 adenomas removed, including $11 \%$ of patients with 33 advanced adenomas. Among 14 patients with advanced adenomas, seven (50\%) developed $\geq 1$ late metachronous cancers.

CONCLUSIONS: Following removal of an incident symptomatic early stage colorectal cancer, the risk of later metachronous neoplasia persists for an extended period more than five years after removal of the incident colorectal cancer. Moreover, risk for late metachronous cancer appears to be predicted by the presence of multiple adenomas or advanced adenomas; most metachronous cancers in this cohort were detected using colonoscopy before onset of symptoms and at an early stage.

Key Words: Advanced adenoma; Colon cancer; Colon polyps, Colonoscopic polypectomy; Metachronous colon cancer; Natural history; Synchronous colon cancer

$\mathrm{M}$ ost patients with colorectal cancer have localized or locally advanced disease, usually leading to a 'curative' resection (1). Later follow-up now includes colonoscopic review guided by updated expert recommendations (2). Because the prognosis for recurrent disease has been disappointing, colonoscopic evaluations in this setting have largely focused on detection of metachronous neoplasms (2).

In extended studies of stage 2 or 3 colorectal cancer, a second primary or metachronous cancer has been estimated to develop in up to

\section{L'évolution naturelle et les issues à long terme des patients traités pour un cancer colorectal de stade précoce}

HISTORIQUE : L'évolution naturelle à long terme du cancer du côlon de stade précoce et l'issue de la surveillance coloscopique à long terme en pratique clinique spécialisée habituelle après l'ablation de cancers primaires ne sont pas pleinement définies. Dans la présente évaluation à long terme sur une période pouvant atteindre 25 ans, les chercheurs ont défini la néoplasie métachrone, y compris à la fois les adénomes et les carcinomes avancés.

MÉTHODOLOGIE : Tous les patients atteints d'un cancer colorectal de stade précoce évalués consécutivement dans une seule pratique clinique ont subi des évaluations coloscopiques de suivi après l'ablation du cancer primaire et la résorption de la maladie néoplasique. La surveillance coloscopique était planifiée en deux phases, d'abord tous les ans pendant cinq ans, puis tous les trois ans jusqu'à un maximum de 25 ans, et incluait l'ablation de toute lésion néoplasique métachrone. RÉSULTATS : Au total, les chercheurs ont évalué 128 patients (66 hommes et 62 femmes) présentant 129 cancers colorectaux primaires de stade précoce, pratiquement tous symptomatiques. Ils présentaient généralement des manifestations cliniques de perte sanguine. Les cancers primaires de stade précoce se situaient un peu partout dans le côlon, notamment dans la région rectosigmoïde, et ne s'associaient pas à des manifestations d'atteinte ganglionnaire ou d'autres métastases. Aucun patient évalué pendant les cinq premières années n’a présenté de récurrence ou de cancer métachrone. Au bout de cinq ans, un total de 94 patients a poursuivi l'évaluation, pendant une période maximale de 25 ans. On a découvert que six de ces patients présentaient sept cancers métachrones du côlon. Tous l'ont contracté plus de sept ans après l'ablation du cancer colorectal primaire, y compris six adénocarcinomes asymptomatiques, dont seulement un s'associait à l'atteinte d'un seul ganglion.Un autre patient de cette cohorte a été touché par un carcinome peu différencié du côlon. De plus, 45 \% des patients ont subi l'ablation d'un total de 217 adénomes, dont $11 \%$ de patients ayant 33 adénomes avancés. Chez les 14 patients ayant un adénome avancé, sept (50\%) ont développé au moins un cancer métachrone tardif.

CONCLUSIONS : Après l'ablation d'un cancer colorectal primaire de stade précoce, le risque de néoplasie métachrone persiste toujours après plus de cinq ans. De plus, le risque de cancer métachrone tardif semble être prédit par la présence de multiples adénomes ou d'adénomes avancés. La plupart des cancers métachrones de cette cohorte ont été décelés par coloscopie à un stade précoce, avant l'apparition des symptômes.

$6.3 \%$ of patients (3-5), while adenomas were recorded in approximately $50 \%(6,7)$. The National Polyp Study (8) established a definite benefit for colonoscopic polypectomy to prevent colorectal cancer, although only adenoma patients, rather than cancer patients, were included. Recently, prevention of deaths attributed to colorectal cancer was also reported after colonoscopic removal of adenomas in these patients (9).

Intervals for colonoscopic surveillance after curative resection of a colorectal cancer remain controversial; however, current guidelines

Department of Medicine (Gastroenterology), University of British Columbia, Vancouver, British Columbia

Correspondence: Dr Hugh James Freeman, University of British Columbia Hospital, 2211 Wesbrook Mall, Vancouver, British Columbia V6T 1W5.

Telephone 604-822-7216, fax 604-822-7236, e-mail hugfree@shaw.ca

Received for publication September 11, 2012. Accepted January 1, 2013 
have recommended that initial follow-up should be more intense in the first five years to exclude missed synchronous cancers or early metachronous neoplasms (2), particularly in individuals with multiple or large neoplastic lesions (10). A number of randomized, but historical, trials from surgical centres have compared intense with less intense surveillance after a 'curative' resection (11-15). Unfortunately, a number of methodological flaws in these studies were noted (1), particularly the inclusion of both early (ie, 'node-negative') and late(ie, 'node-positive') stage disease together in the different groups being compared, regardless of the intensity of subsequent follow-up. Evaluation of more homogeneous populations, particularly with early stage disease, would have been optimal because the prognosis for patients with nodal involvement, invasion of other structures and distant metastases is more guarded. Although a survival benefit with intense follow-up has been established (16), longer-term data from such high-risk populations more than five years following colorectal cancer resection remain limited.

The present study focused on early stage colorectal cancer patients without evidence of nodal involvement or other metastases. Consecutive patients were evaluated for up to 25 years during the course of a single clinical practice experience to detect recurrent cancer or any new metachronous neoplasms, including second (or more) colorectal cancers.

\section{METHODS}

\section{Patient population}

All patients diagnosed with early stage 'sporadic' colorectal cancer by the investigator during a 25-year period from July 1980 to June 2005 were consecutively evaluated with the total follow-up period progressing for up to 25 years to June 2010. Before treatment, all patients underwent standard laboratory tests including a hemogram, liver chemistry tests and carcinoembryonic antigen (CEA) determination. In addition, radiological imaging studies, including computed tomography (CT) scanning, were completed. All patients had colorectal cancer established by a pathologist with expertise in diagnosis and pathological staging of colon cancer using an established classification method (TNM system, American Joint Committee on Cancer). Patients with a perforating cancer or metastatic disease, including those with lymphatic invasion or lymph node involvement, adherence to adjacent structures or invasion into adjacent or peripheral structures, were excluded from the present evaluation even if a 'curative' surgical resection was performed.

Early stage colorectal cancer was defined on the basis of pathological assessment of the resected colon and lymph nodes; however, some patients were treated only with colonoscopic polypectomy and have been reported in detail elsewhere (17). In these polypectomy patients, lymph nodes could not be examined unless a further surgical resection was performed to ensure complete excision (based on a $2 \mathrm{~mm}$ clearance margin from the cautery margin for malignant polyps). In all patients, CEA studies were normal and CT scanning showed no evidence of lymph node or metastatic disease.

Exclusion criteria also included a personal or familial history of inflammatory bowel disease, including either ulcerative colitis or Crohn disease, or a previous family history of colon neoplasia including colorectal polyps or colorectal cancer.

\section{Colonoscopic evaluations}

All patients underwent a 'clearing' colonoscopy usually before cancer resection or, in some, within six months of cancer removal. Subsequently, annual colonoscopy was planned for the next five years with removal of visualized polyps and, if colonoscopy failed to reveal any neoplastic disease at the five-year colonoscopy, addititonal colonoscopies were subsequently scheduled every three years. If neoplastic disease was detected at the five-year colonoscopy, annual colonoscopic evaluation was planned until no neoplastic disease was detected, and colonoscopies were subsequently planned for every three years. Cessation of follow-up after completion of this initial five-year period was arbitrary but was offered to each patient depending on clinical assessment related to age, patient desire to continue as well as development of other concomitant comorbidities (eg, other malignancies, significant cardiopulmonary disease, dementia).

All patients underwent colonoscopies and removal of all visualized polyps after a standard bowel preparation was completed; a consent form for colonoscopy and polypectomy was signed before each procedure. This approval also specified that any information generated from these procedures could also be used for quality assurance review, including medical reporting. Most patients were administered a combination of intravenous sedative and narcotic before the procedure; some requested that the procedure be performed without medication.

Over the extended period of the present study, both standard and high-definition colonoscopes were used. At each colonoscopy, the size and location of each neoplastic polyp was defined and removed, with pathological evaluation performed to confirm the presence of neoplastic change (adenoma, tubulovillous adenoma, villous adenoma). Biopsies were also routinely obtained during each colonoscopy from the surgical anastomoses to exclude any microscopic recurrent cancer.

\section{Definitions}

Synchronous colon cancer was defined as a second colon cancer detected at the time of the initial colon cancer diagnosis, while metachronous colon cancer was defined as any subsequent colon cancer detected during the follow-up period.

Neoplastic polyps (tubular adenoma, tubulovillous adenoma, villous adenoma) were also defined as advanced polyps based on one or more of the following criteria: size $>1 \mathrm{~cm}$; pathological detection of villous components; or severe dysplasia (10).

\section{End dates of evaluations and statistical analysis}

Each patient was considered to have 'complete' data for the initial five-year period if four colonoscopies were performed within the first five years of follow-up after the incident colorectal cancer was resected. A patient completing fewer than four colonoscopies in the initial five-year period was considered to have 'incomplete' data. After five years, only patients from the initial five years up to the end of the study in June 2010 were included. Statistical analyses were performed using $\chi^{2}$ or the Student's $t$ test.

\section{Patient sex, age and race}

\section{RESULTS}

A total of 128 patients with a pathologically confirmed diagnosis of colorectal adenocarcinoma, defined as early colorectal cancer, were evaluated in the present long-term study.

The entire study cohort is represented in Figure 1, based on age at diagnosis of colorectal cancer. Most men and women in the present evaluation were 50 to 79 years of age. There were 66 men $(51.6 \%$, mean age 63.5 years; median age 62 years), and 62 women (mean age 64.8 years; median age, 62 years) ranging in age from 29 to 86 years at the time of initial diagnosis of early stage colon cancer. Of these, 114 patients $(89.1 \%)$, were Caucasian. There were also 13 Asian patients (seven male and six female) and one First Nations male.

While familial or inherited cases of colon cancer were excluded, the present evaluation included an otherwise healthy married couple (ie, 'marital colon cancer') - an 86-year-old man with a stage 1 cecal cancer (T1NOMO) and a 74-year-old woman with a stage 1 sigmoid cancer (T1NOM0). The woman was initially diagnosed in 2005 after presenting with rectal bleeding, followed by her asymptomatic husband later in the same year, referred for a screening procedure. Both later completed an additional five years of planned follow-up.

\section{Symptoms with incident and metachronous colon cancer}

All patients, except for the asymptomatic man noted above, were diagnosed with the initial colon cancer after presentation with one or more symptoms. A total of 96 (75\%) patients had evidence of colonic blood loss, usually as intermittent rectal bleeding, occult blood-positive stools or iron deficiency-associated anemia. In some, this was associated with 
chronic use of an anticoagulant medication, specifically, warfarin. A total of 37 (29\%) patients described poorly localized abdominal pain or discomfort, while 29 (23\%) reported a change in bowel habit, either diarrhea, constipation or increased stool frequency.

All patients later found to have a metachronous colon adenocarcinoma were asymptomatic, while one patient with intermittent abdominal pain and diarrhea during and after foreign travel in Europe, and previously reported (18), experienced a later neuroendocrine carcinoma of the colon.

\section{Incident colon cancers}

Of 129 incident colon cancers detected in 128 patients (one 38-yearold woman with two synchronous colon cancers in the descending colon, both T1NOM0), all were adenocarcinomas. For this cohort, the majority $(n=82[63 \%])$ of incident early colorectal cancers were localized in the rectosigmoid, while $13(10 \%)$ were localized in the descending colon and six $(5 \%)$ in the transverse colon. The remaining $28(22 \%)$ were localized in the right colon (cecum and ascending colon). If the rectosigmoid and descending colon cancers were classified as left colon, most early colorectal cancers in this cohort (ie, $>75 \%$ ) were located there, significantly greater than the number of early colon cancers in the right colon, specifically cecum and ascending colon $(\mathrm{P}<0.05)$. The sex distributions for each of these colon sites (ie, rectosigmoid, descending colon, transverse colon, right colon (cecum and ascending colon) were similar.

Pathology of the resected specimens noted that all incident early colorectal cancers were well-differentiated or moderately differentiated adenocarcinomas. In addition, mucinous components were noted in five of 28 (approximately $18 \%$ of right-sided colon cancers) and three of nine $(3 \%)$ colorectal cancers in the sigmoid or descending colon $(\mathrm{P}<0.05)$. Of 129 cancers in the 128 patients with early stage colorectal cancer, $68 \%$ of right-sided colon cancers were reported to extend into the muscularis propria, not significantly different from $55 \%$ of cancers in the descending colon and rectosigmoid. No differences were noted between men and women.

Treatment of incident early colorectal cancers

Of the 128 patients, 103 (>80\%) underwent resection for their cancer. The other 25 were treated with colonoscopic polypectomies using snare cautery; however, five of these $25(20 \%)$ required an additional colon resection to ensure complete removal of the incident colon cancer. The other 20 patients treated with colonoscopic polypectomy did not undergo additional surgical resective treatment because the cautery margin was pathologically assessed to be $>2 \mathrm{~mm}$ from the cancer margin. Of the five who underwent further resective surgery, only one had a focus of neoplastic cells localized within the submucosa in the resected colon surgical specimen that had not extended into the muscularis propria. All procedures in this selected cohort of 128 early colorectal cancer patients were considered to be 'curative' and no other adjuvant therapies were provided.

\section{Patient follow-up during the initial five years}

A total of 124 of 128 (97\%) of patients completed the initial five-year follow-up phase with at least four or five colonoscopic evaluations each. In 124 of these, the final colonoscopy was scheduled and completed in the fifth year of follow-up. Collectively, 590 colonoscopies were satisfactorily completed with no procedure-related complications, including perforation or bleeding. No patient in this cohort of 128 was found to have macroscopic or histological evidence of recurrent cancer. Among the patients lost to follow-up (incomplete data) during the initial five years, there were two men - age 69 years (diagnosis, T2, 1997) and 77 years (diagnosis, T1, 2005) - each with follow-up data for three years after the initial colon cancer diagnosis, and two women - age 85 years (diagnosis, T3, 2002) and 83 years (diagnosis, T1, 2000) - with two years and three years, respectively, of completed follow-up data available. None of these four patients demonstrated evidence of recurrent colon cancer. The first man died suddenly in a private single passenger airplane accident following his

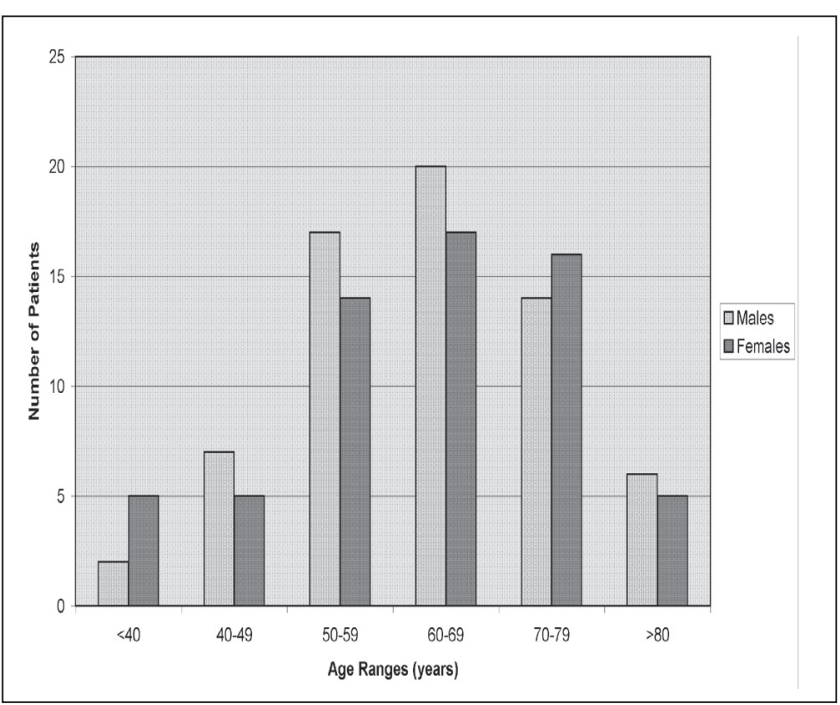

Figure 1) Males and females in each age group ( $n=128$ patients)

third colonoscopy while the second man developed a neuroendocrine carcinoma of the bladder following his third colonoscopy, which led to an end to further colonoscopic evaluations and his death from the bladder cancer two years later. The first woman was lost to follow-up after her second annual review and colonoscopy, while the second woman underwent three subsequent colonoscopic evaluations but refused further follow-up evaluations.

\section{Patient follow-up after five years}

Of the 124 patients who completed the first five years of follow-up after the initial cancer resection, 94 (almost 80\%) were evaluated from six to 25 years. The mean duration of follow-up was 11.7 years from the cancer resection. After the initial five-year period, an additional 351 colonoscopies were satisfactorily completed without any procedurerelated complications, including perforation or bleeding. Figure 2 illustrates the patients seen from six to 25 years of follow-up. A total of 30 were not evaluated beyond five years due to patient preference, advanced age with or without other significant comorbidities. Of 94 patients evaluated after five years, 38 were followed for a total of six to nine years, 32 for 10 to 14 years, 18 for 15 to 19 years, and six for $>20$ years before the conclusion of the present study. Of these six patients, one was evaluated for 25 years.

This cohort of 94 patients evaluated for $\geq 6$ years consisted of 47 men (mean age 60.7 years; median age 62 years) and 47 women (mean age 58.2 years; median age 61 years), who ranged in age from 29 to 81 years at the time of initial diagnosis of early stage colon cancer. Thus, 19 men and 15 women were not evaluated after five years (including two men and two women originally lost to follow-up in the first five years). Figure 3 reports the age ranges of men and women in this final cohort of 94 patients. As shown, and as might be expected, most patients who did not continue with ongoing evaluations after five years were elderly, age $\geq 70$ years, with only 20 of the original $41(<50 \%)$, for these two elderly age groups. For site distribution in this final cohort, a total of 14 of 29 patients with an incident right colon cancer (cecum and/or ascending colon $[<50 \%$ for this site]) continued with more than five years of follow-up. All other sites each had at least two-thirds of the original cohort with continued follow-up for $>5$ years.

\section{Synchronous and metachronous colon cancers}

Of the 128 patients, a single 38-year-old woman had synchronous colon cancers in two sites on the initial colonoscopy (ie, synchronous colon cancer detection rate $<1 \%$ ). These were located approximately $3 \mathrm{~cm}$ apart in the descending colon. Both cancers were pathologically confirmed as early stage colon cancers in the resected colon specimen (both $\mathrm{T} 1$ only). 


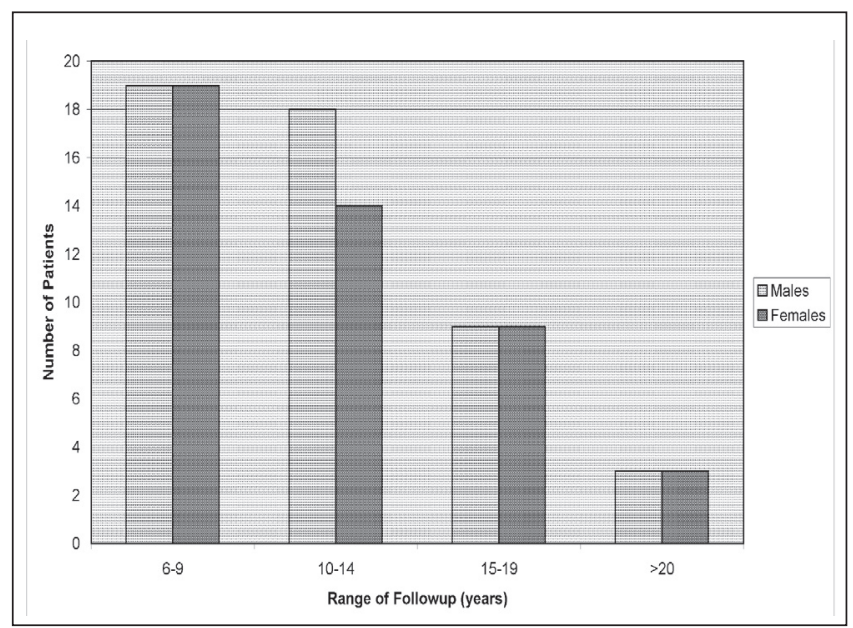

Figure 2) Range of follow-up after the initial five-year period ( $n=94$ patients)

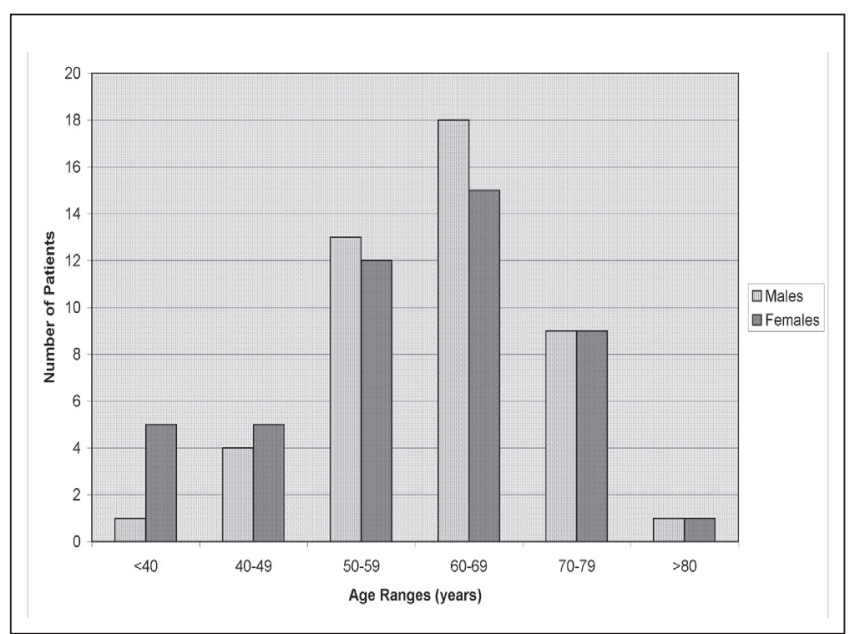

Figure 3) Males and females in each age group evaluated for more than five years ( $n=94$ patients)

During their follow-up evaluations, six other patients (approximately 5\%) were later discovered to have seven metachronous colon cancers (including five men with six cancers). These are detailed further in Table 1, and all of these were surgically resected. One woman and one man also received added chemotherapy. Of these seven cancers, six were reported as well-differentiated or moderately well-differentiated adenocarcinomas. All of these adenocarcinomas were asymptomatic, being detected during colonoscopic evaluation $\geq 7$ years after the initial colon cancer was defined. In a woman treated with added chemotherapy, single-node involvement was detected with a cecal cancer. In one man, intermittent diarrhea initially developed during foreign travel in Europe, and a poorly differentiated neuroendocrine carcinoma in the ascending colon with liver metastases was detected $>20$ years after the initial colon cancer resection. Of note, after his resection of the incident colorectal cancer, he was treated in the interval for prostate cancer and, later, a B cell lymphoma with a chemotherapy regimen that included added rituximab, a B cell-depleting monoclonal agent (18). In addition to resection of his second colon cancer, he was treated with chemotherapy using a cis-platinumbased regimen. In one other man, there were two metachronous colon cancers. These appeared seven and 13 years after the initial colon cancer was diagnosed and resected. Thus, in the 128 patients in the present study, a total of 135 colon cancers were detected, including a single poorly differentiated colonic neuroendocrine carcinoma.
TABLE 1

Late metachronous colon cancers following early stage colon cancer

\begin{tabular}{lcccc}
\hline $\begin{array}{l}\text { Age, yearsl } \\
\text { sex }\end{array}$ & $\begin{array}{c}\text { Year Dx for } \\
\text { incident CA }\end{array}$ & Site-stage & $\begin{array}{c}\text { Year Dx for } \\
\text { metach CA }\end{array}$ & Site-stage \\
\hline 72/male* & 1997 & Sigmoid-T3 & 2004 & Descending-T2 \\
29/male & 1990 & Cecum-T3 & 2003 & Sigmoid-T1 \\
62/male & 1988 & Transverse-T3 & 1996 & Cecum-T3 \\
61/female & 1997 & Sigmoid-T1 & 2006 & Cecum-T3 $^{\dagger}$ \\
61/male & 1991 & Sigmoid-T1 & 1999 & Cecum-T1 \\
58/male & 1991 & Sigmoid-T2 & 2011 & Ascending $^{\ddagger}$ \\
\hline
\end{tabular}

*Another metachronous cancer diagnosed (Dx) 2010 in the cecum (T3); ${ }^{\dagger}$ Cecal cancer with one of 12 resected lymph nodes positive; ${ }^{\ddagger}$ Advanced neuroendocrine carcinoma involving lymph nodes and liver. CA Colon cancer; Metach Metachronous; TNM classification: T1, T2, T3; unless noted below, all NOMO

TABLE 2

Advanced adenomas and metachronous colon cancer

\begin{tabular}{lcccl}
\hline \multirow{2}{*}{$\begin{array}{l}\text { Age, years } \\
\text { sex }\end{array}$} & Adenomas & $<5$ years & $>5$ years & Cancer \\
\cline { 2 - 4 } 62/female & 1 & 0 & 1 & 0 \\
72/male & 10 & 1 & 1 & DC and cecum \\
67/male & 9 & 9 & 0 & 0 \\
74/male & 4 & 1 & 1 & 0 \\
42/female & 4 & 0 & 2 & Small bowel \\
65/male & 11 & 1 & 1 & 0 \\
29/male & 8 & 1 & 2 & Sigmoid \\
58/male & 8 & 0 & 2 & 0 \\
58/male & 3 & 0 & 1 & Neuroendo \\
68/male & 3 & 1 & 1 & 0 \\
62/male & 3 & 1 & 0 & Cecum \\
38/female & 26 & 0 & 2 & 0 \\
61/female & 5 & 3 & 0 & Cecum \\
61/male & 8 & 0 & 1 & Cecum
\end{tabular}

DC Descending colon; Neuroendo Neuroendocrine carcinoma

Other gastrointestinal cancers

Of note, one woman later developed a fatal small intestinal adenocarcinoma 10 years after the initial colon cancer was resected. No other gastric or intestinal malignancies were detected; however, one woman also demonstrated a $1 \mathrm{~cm}$ to $2 \mathrm{~cm}$ pancreatic cystic neoplasm on her initial CT scan. Annual imaging studies have not defined any significant change in size in the pancreatic lesion over five years.

Other colonic neoplastic lesions

Collectively, there were a total of 217 adenomas resected in 128 patients; 33 (approximately 15\%) could be classified as advanced adenomas as noted elsewhere (10). Most adenomas (124 of 217 [>50\%]) were removed $>5$ years after the incident colorectal cancer was resected.

Forty-three of 128 patients $(33.6 \%)$ in the first five years after colon cancer resection had $93(42.8 \%)$ of the adenomas resected. After five years, 37 (39.4\%) of 94 remaining patients had 124 more adenomas resected. A total of 33 advanced adenomas were detected and removed in 14 patients. This included 18 in the first five years in eight patients and 15 after five years in 11 patients.

Table 2 presents 14 patients with advanced adenomas removed during the first five years and after five years. Of these, seven patients (50\%) eventually developed a metachronous colon cancer, including six with asymptomatic colonic adenocarcinomas.

Another woman developed a small bowel adenocarcinoma that was resected. In addition, 13 of these 14 patients had multiple adenomas and 10 had multiple advanced adenomas. Finally, a total of 103 adenomas were removed from these 14 patients, corresponding to $47.5 \%$ of all of the adenomas detected and removed in this cohort. 


\section{DISCUSSION}

The present study explored the long-term natural history of symptomatic early ('node-negative') colorectal cancer after resection. End points for evaluation included detection of recurrent cancer, synchronous cancer, metachronous cancer and adenomas, including advanced adenomas. In contrast to previous historical reports describing significant rates of cancer recurrence (despite intense annual surveillance) in patients with different stages of the disease (3-6), the present evaluation found no recurrent disease. This is not surprising because the present cohort was highly selected, representing a more homogenous early stage colorectal cancer population than earlier studies with no local or distant metastases, or nodal involvement. The patients in the present study, however, remained at high risk for later metachronous neoplasms, including both advanced adenomas and new metachronous colon cancers.

Seven new metachronous colorectal cancers developed late in six patients, after the initial five years of surveillance. In these patients, cancers developed seven years to $>20$ years following resection of the incident colon cancer. All of these patients had their initial studies performed for symptomatic disease, while all six metachronous adenocarcinomas were asymptomatic and only discovered by colonoscopic evaluation. Interestingly, most incident colon cancers (including patients with late developing metachronous cancers) were located in the sigmoid colon compared with metachronous colon cancers, which were usually detected in the ascending colon and cecum. Finally, the findings in the present study also contrast with a previous surgical centre report noting that metachronous colorectal cancers tend to appear at a later TNM stage than incident colorectal cancers (19). In the present report, most metachronous colon adenocarcinomas were detected at an early rather than a late TNM stage, even though one patient with a previous malignant sigmoid polyp had already developed localized single node involvement from a metachronous cecal cancer. This may have been a late interval cecal cancer detected in the eighth year of follow-up, three years after her last colonoscopy following removal of a malignant sigmoid polyp, as reported elsewhere (20).

\section{REFERENCES}

1. Meyerhardt JA, Mayer RJ. Follow-up strategies after curative resection of colorectal cancer. Semin Oncol 2003;30:349-60.

2. Rex DK, Kahi CJ, Levin B, et al. Guidelines for colonoscopy surveillance after cancer resection: A consensus update by the American Cancer Society and US Multi-Society Task Force on Colorectal Cancer. Gastroenterology 2006;130:1865-71.

3. Luchtefeld MA, Ross DS, Zander JD, Folse JR. Late development of metachronous colorectal cancer. Dis Colon Rectum 1987;30:180-4.

4. Cali RL, Pitsch RM, Thorson AC, et al. Cumulative incidence of metachronous colorectal cancer. Dis Colon Rectum 1993;36:388-93.

5. Green RJ, Metlay JP, Propert K, et al. Surveillance for second primary colorectal cancer after adjuvant chemotherapy: An analysis of Intergroup 0089. Ann Intern Med 2002;136:261-9.

6. Chen F, Stuart M. Colonoscopic follow-up of colorectal carcinoma. Dis Colon Rectum 1994;37:568-72.

7. Neugut AI, Lautenbach E, Abi-Rached B, Forde KA. Incidence of adenomas after curative resection for colorectal cancer. Am J Gastroenterol 1996;91:2096-8.

8. Winawer SJ, Zauber AG, Ho MN, et al. Prevention of colorectal cancer by colonoscopic polypectomy. The National Polyp Study Workgroup. N Engl J Med 1993;329:1977-81.

9. Zauber AG, Winawer SJ, O’Brien MJ, et al. Colonoscopic polypectomy and long-term prevention of colorectal-cancer deaths. N Engl J Med 2012;366:687-96.

10. Martinez ME, Baron JA, Lieberman DA, et al. A pooled analysis of advanced colorectal neoplasia diagnoses after colonoscopic polypectomy. Gastroenterology 2009;136:832-41.

11. Pietra N, Sarli L, Costi R, Ouchemi C, Grattarola M, Peracchia A. Role of follow-up in management of local recurrences of colorectal cancer: A prospective, randomized study. Dis Colon Rectum 1998;41:1127-33.
Even this patient, however, was asymptomatic amenable to a further 'curative' resection and adjuvant chemotherapy. Subsequent blood studies, including CEA testing, CT scans and two additional colonoscopies have been normal.

In the present evaluation, detection of metachronous neoplasms was not limited to malignant lesions. Not surprisingly, given the extended duration of colonoscopic surveillance studies, the number of adenomas, including advanced adenomas, was significant. Collectively, approximately $45 \%$ of patients had adenomas and $11 \%$ had advanced adenomas detected and removed during follow-up after resection of the incident cancer.

Importantly, most of these adenomas, including advanced adenomas, were discovered $>5$ years after the original resection during a period of less-intense follow-up. In this selected group with early incident colorectal cancer, extended periods, even life-long follow-up after five years may be indicated to exclude both metachronous cancers and adenomas, including higher-risk advanced adenomas.

The present study did not evaluate guidelines for surveillance colonoscopy in patients with previous colon cancer. In fact, during the course of the present evaluation, the guidelines have evolved. To some degree, the present study supports current postresection guidelines for an increased intensity for colonoscopy surveillance, at least in the initial five years following surgical treatment. However, the present report also extends important observations of others to optimize outcomes (20), especially five years or more after removal of the incident colon cancer. Among patients in the present evaluation who eventually developed a metachronous cancer, all had a pre-existent phenotype including either multiple adenomas, advanced adenomas or both. In fact, in the present cohort, $50 \%$ of patients with multiple adenomas or advanced adenomas eventually developed a metachronous cancer, which was usually asymptomatic and at an early stage. These appeared to represent a special high-risk group, warranting consideration for more intense follow-up regardless of the duration following the initial colon cancer removal.

12. Makela JT, Laitenen SO, Kairaluoma MI. Five-year follow-up after radical surgery for colorectal cancer. Results of a prospective randomized trial. Arch Surg 1995;130:1062-7.

13. Ohlsson B, Breland U, Ekberg H, Graffner H, Tranberg KG. Follow-up after curative surgery for colorectal carcinoma. Randomized comparison with no follow-up. Dis Colon Rectum 1995;38:619-26.

14. Schoemaker D, Black R, Giles L, Toouli J. Yearly colonoscopy, liver $\mathrm{CT}$, and chest radiography do not influence 5 -year survival of colorectal cancer patients. Gastroenterology 1998;114:7-14.

15. Kjeldsen BJ, Kronborg O, Fenger C, Jorgensen OD. A prospective randomized study of follow-up after radical surgery for colorectal cancer. Br J Surg 1997;84:666-9.

16. Jeffery M, Hickey RE, Hider PN. Follow-up strategies for patients treated for non-metastatic colorectal cancer. Cochrane Database Syst Rev 2007;(1):CD002200.

17. Freeman HJ. Long-term follow-up of patients with malignant pedunculated colon polyps after colonoscopic polypectomy. Can J Gastroenterol 2012;27:20-4.

18. Freeman HJ, Kwan PWC, Webber D. Large-cell neuroendocrine cancer of the colon following rituximab-based lymphoma treatment. Can J Gastroenterol 2012;26:12-13.

19. Yoon JW, Lee SH, Ahn BK, Baek SU. Clinical characteristics of multiple primary colorectal cancers. Cancer Res Treat 2008;40:714.

20. Rulyak SJ, Lieberman DA, Wagner EH, Mandelson MT. Outcome of follow-up colon examination among a population-based cohort of colorectal cancer patients. Clin Gastroenterol Hepatol 2007;5:470-6. 


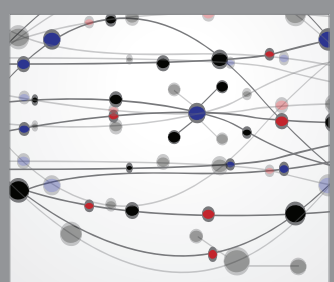

The Scientific World Journal
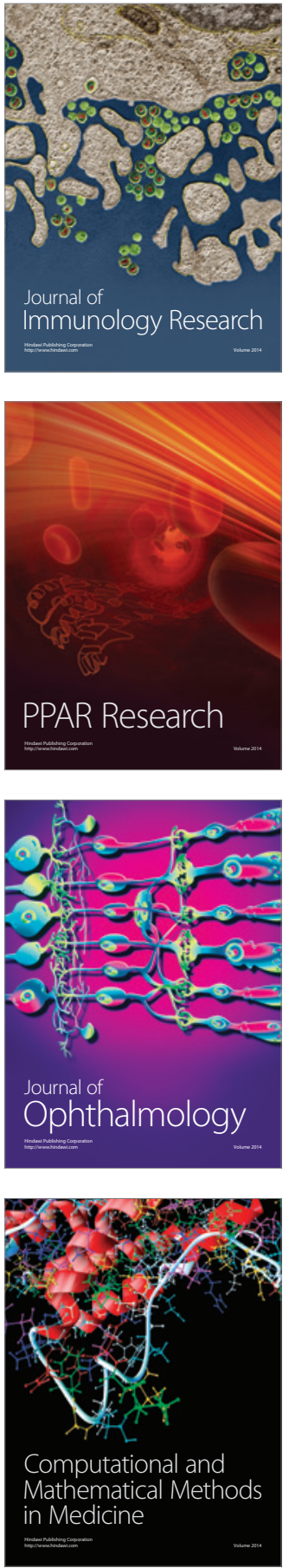

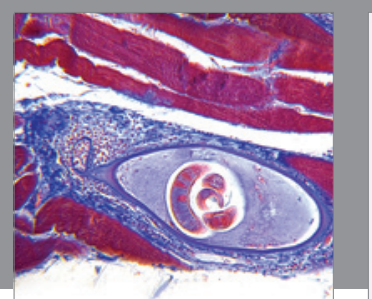

Gastroenterology Research and Practice

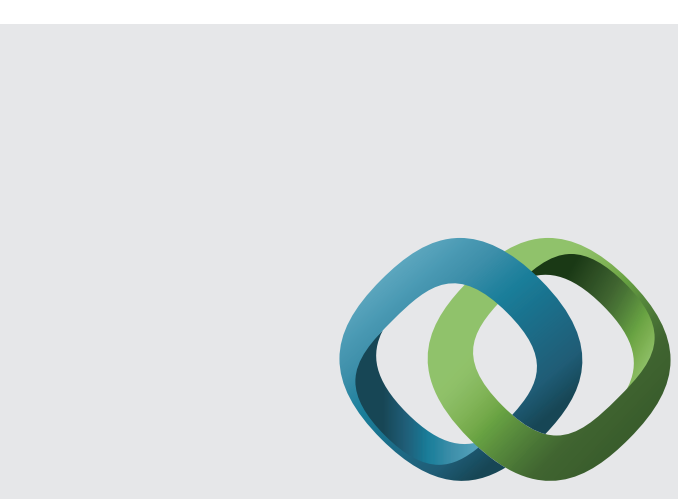

\section{Hindawi}

Submit your manuscripts at

http://www.hindawi.com
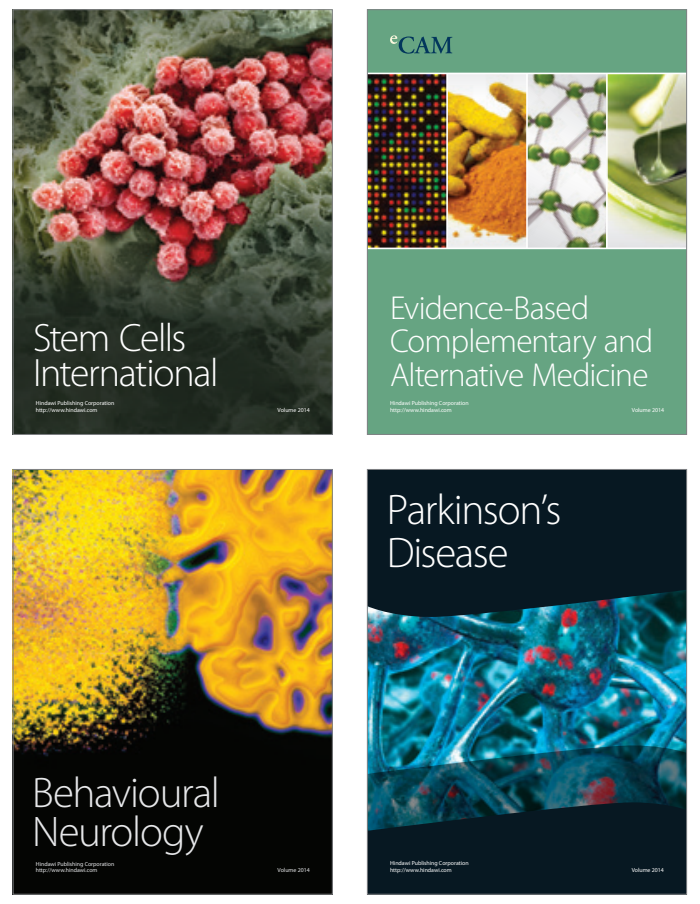
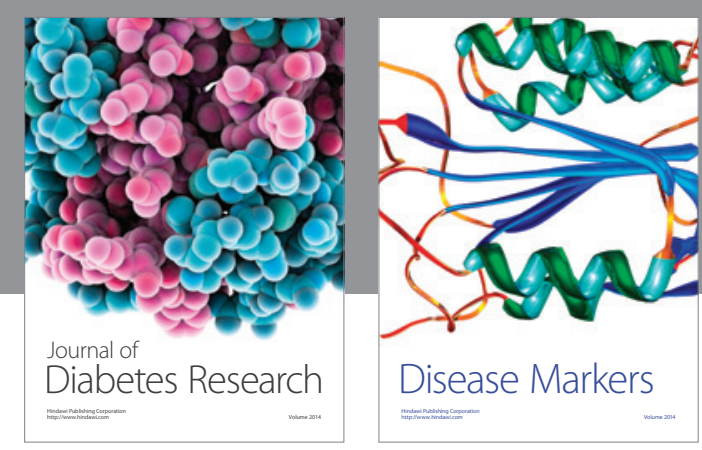

Disease Markers
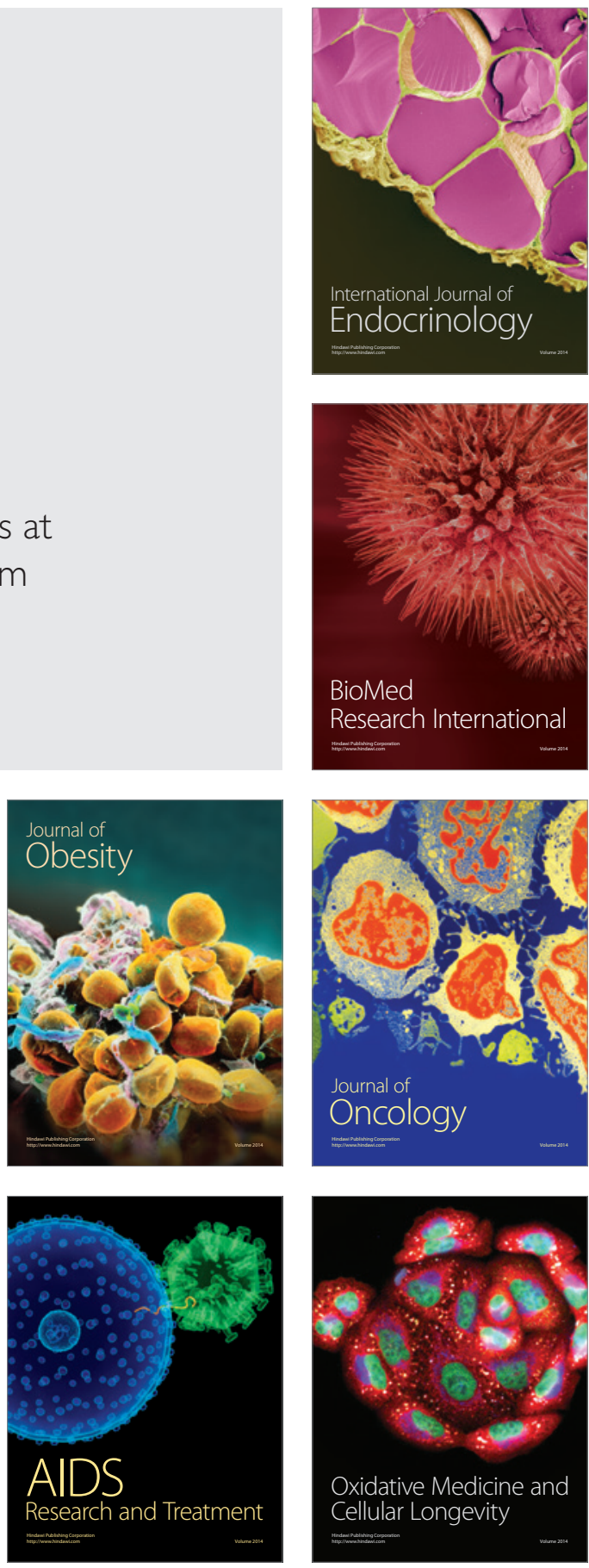